\title{
AN ANALYSIS ON ANTISOCIAL PERSONALITY DISORDER OF KEVIN IN "WE NEED TO TALK ABOUT KEVIN MOVIE DIRECTED" BY LYNNE RAMSAY
}

\author{
Suhendar \\ STIBA IEC Jakarta \\ suhendar_success@yahoo.com \\ Agung Hermawan \\ STIBA IEC Jakarta \\ hermawanagungaja@gmail.com
}

\begin{abstract}
The aim of this analysis is to know and understand the criteria, causes, influence, characters and moral messages of Kevin in Analysis on Antisocial Personality Disorder of Kevin in "We Need to talk about Kevin Movie Directed by Lynne Ramsay". This method uses descriptive qualitative analysis. The analytical results obtained are: (1) Criteria of antisocial personality disorder of Kevin namely among the other things deceitfulness, irritability, aggressiveness, reckless, disregard for safety of his own self or for others and lack of remorse. (2) The causes of antisocial personality disorder on Kevin is less responsive (genetic) and neglect of family on Kevin (Environment). (3) Kevin's behaviour influencing the others is posing of a threat and (4) Moral message that people should anticipate with antisocial personality disorder is that people should not hurt the person and should communicate with him very well. As a result, Kevin has the characters of aggressiveness, easily lying and can injure others without feeling any guilt.
\end{abstract}

\section{Keywords: Antisocial Personality Disorder, Disregard for safety}

\section{A. INTRODUCTION}

\section{Background}

English as such an international and global language strategically gives a delightful contribution for human being in expressing and actualizing their imagination and actualization into many purposes, one of which is in expressing and actualizing their purpose in film. Accordingly, English can be categorized as a productive language 
for many people in the world to pleasingly precede their purposes into more specific intension like film or movie.

In relation to which, antisocial personality disorder is someone who has trouble of thinking and perceiving in social life, they are not able to conduct as a common human. Antisocial personality disorder is also one of mentality disturbance which shows impulsive, irresponsible, regardless, deviant, and unruly characters. This individual can be categorized into personality disorder which has different character with the other personality disorder.

In few of that, this disorder involves a persistent pattern of distorted ways of thinking, feeling and acting that causes people to engage harmful and often violent actions without feeling guilty. The antisocial person seeks to satisfy his or her own immediate interests with little or no regard for law or social consequences. The disorder is called antisocial because the person attacks society and its people.

The disorder usually begins in childhood or as a teen and continues into a person's adult. There are two causing factors of antisocial personality disorder; first is genetic factor which is suspected to be influenced from antisocial biological parent. Second is environmental factor which is believed to contribute the development of antisocial personality disorder as the person can socialize and get social interaction with the environment which has role model of antisocial tendencies. Psychologically, personality disorder has more and less seven criteria which are among the other things as follows: Repeated criminal acts, Deceitfulness, Impulsivity, Irritability, Aggressiveness, Recklessness, Irresponsibility and Lacks remorse Personality disorders are divided into fourteen types of personality disorder, there are : Schizoid personality disorder, Avoidant personality disorder, Depressive personality disorder, Dependent personality disorder, Histrionic personality disorder, Narcissistic personality disorder, Antisocial personality disorder, Sadistic personality disorder, Compulsive personality disorder, Negativistic personality disorder, Masochistic personality disorder, Paranoid personality disorder, Schizotypal personality disorder and Borderline personality disorder.

\section{Objectives}

In view of the background stated hereinabove, the objectives of this study are to find out the criteria of antisocial personality disorder of We Need to Talk About 
Kevin, to know the causes of antisocial personality disorder happening on Kevin and to elaborate how Kevin's character influence others.

\section{Theoretical Framework}

\subsection{Character}

Through entertainment program movie can be deemed successful if it is supported by a good idea and character. Character is one of important role in movie. Through the character, the story of movie can be understood and easy to be analysed by viewer, hence, the viewer will automatically know how a movie can explain about. Accordingly, character is always improved from year to year with the appearing of new actors or actresses as well as the modern style thereof. Without character, there is no story to tell about.

According to Abbott (2008:130) "Character is one of the two principal components in most stories, the other being the action". The theory tells that characters are the important components in the stories.

Bohner (2006:9) Said that, "Character is the most important element, as least as far as grabbing the interest of general reader. Often on a first reading of a story, the characters are what determine if we enjoy the experience of reading the story or not". From the statements above, character is one of important elements, often on a first reading of a story. Based on Lucke (1998:30) "Character is the first essential ingredient in any successful story. Your idea won't come alive, won't begin to become a story, until some characters claim it as their own. The story comes out of their motives, their desires, their actions and interactions and reaction". The writer assumes that character is the first essential ingredient in any successful story, then story come out of their motives.

\subsection{Personality Disorders}

Personality disorder has definition in each aspect and criteria. Commonly, the list of criteria for personality disorder is for about seven, eight, or nine items. Which are telling detail about characteristic, attitude and behaviour. A person with personality disorder has trouble thinking and perceiving, it relates to the situation and condition 
around them. Personality disorder appears begin in the teenage years of early adulthood.

According to Dobbert (2010:1) "Personality Disorder is an enduring pattern of inner experience and behaviour that deviates markedly from the expectations of the individual's culture, it is pervasive and inflexible, it has an onset in adolescent or early adulthood, it is stable over time, and it leads to distress or impairment". It means that personality disorder is enduring pattern of inner experience and behaviour which deviates markedly from the expectation of the individual's culture.

Wood (2010:7) said "Personality Disorders are characterized by rigid, inflexible patterns of thinking and behaving that begin as early as childhood or adolescence and cause continual distress throughout many areas of a person's life." From the statement above, personality disorder is inflexible pattern of thinking and behaving that appear while adolescence.

Feldman (2011:529) Explained "Personality disorder is characterized by as set of inflexible, maladaptive behaviour pattern that keep a person from functioning appropriately in society". It can be shown that personality disorder is characterized by a set of inflexible and maladaptive behaviour pattern. From all statements above, the author concludes that personality disorder is emotion and aggressive of a person who has trouble of thinking. It appears when adolescence and influence of main character comes.

Based on Millon (2004:4) personality disorders are divided into fourteen types of personality disorder, which are among the other things as follows:

1) Schizoid personality disorder: apathetic, indifferent, remote, solitary. Neither desires nor need human attachments. It is minimal awareness of feelings of self or others.

2) Avoidant personality disorder: hesitant, self-conscious, embarrassed and anxious. It is tense in social situations due to fear of rejection.

3). Depressive personality disorder: sombre, discouraged, pessimistic, brooding, fatalistic. Present self as vulnerable and abandoned. 
4) Dependent personality disorder: helpless, incompetent, submissive, immature. It withdraws from adult responsibilities. It sees self as weak.

5) Histrionic personality disorder: dramatic, seductive, shallow, stimulus seeking, vain. It overacts to minor events.

6) Narcissistic personality disorder: egotistical, arrogant, grandiose, and insouciant.

7) Antisocial personality disorder: impulsive, irresponsible, deviant, and unruly. Acting without due consideration. Meeting social obligations only when it is self-serving.

8) Sadistic personality disorder: Explosively hostile, abrasive, cruel, dogmatic.

9) Compulsive personality disorder: restrained, conscientious, respectful, and rigid.

10) Negativistic personality disorder: resentful, contrary, sceptical, discontented.

11) Masochistic personality disorder: deferential, pleasure-phobic, servile, blameful, self-effacing. Encourages others to take advantage.

12) Paranoid personality disorder : guarded, defensive, distrustful and suspiciousness. Hyper vigilant to the movies of others to undermine or do harm.

13) Schizotypal personality disorder: eccentric, self-estranged, bizarre.

14) Borderline personality disorder: unpredictable, manipulative, unstable

The statements above tell that personality disorder can be divided into fourteen kinds of personality. There are schizoid, avoidant, depressive, dependent, histrionic, narcissistic, antisocial, sadistic, compulsive, negativistic, masochistic, paranoid, schizotypal, and borderline. Those personalities have its own characteristic in each personality. 
Based on two explanations above, the writers conclude that personality disorders are combined into three elements. Cluster A, cluster B, and cluster C. On the other side, personality disorders also have fourteen types, schizoid, avoidant, depressive, dependent, histrionic, narcissistic, antisocial, sadistic, compulsive, negativistic, masochistic, paranoid, schizotypal, and borderline.

\subsection{Understanding Antisocial Personality Disorder}

Antisocial personality disorder is one of disturbance of mentality which shows impulsive, irresponsible, no regard, deviant, and unruly characters. This individual can be categorized into personality disorder which has different character with the other personality disorder.

According to Frederick (2006:6):

An arrogant and inflated self-image is often manifested as being extremely opinionated and cocky. These patient are often glib, charming, and verbally facile. Many patients who meet criteria for an APD diagnosis are impulsive and have a history of aggressive or violent behaviour. They are often irresponsible in relationships and with respect to obligations to others and exploit others to their own ends.

It means that antisocial personality disorder is someone who is arrogant, aggressive, violent behaviour, and irresponsible in relationship. Based on Richard $(1994: 61)$

An antisocial personality disorder involves a persistent pattern of distorted ways of thinking, feeling and acting that causes people to engage harmful and often violent actions without feeling guilty. The antisocial person seeks to satisfy his or her own immediate interests with little or no regard for law or social consequences. The disorder is called antisocial because the person attacks society and its people.

From the theory above, it can be said that antisocial personality disorder is a disturbance of thinking which is dangerous in nature because they can attack society and its people. 
The writer assumes that antisocial personality disorder is characterized by a long pattern of disregard to other people's right, crossing the line, and violating those rights. From the statement and explanation above it can be concluded that antisocial personality disorder is a person who gets disturbance of thinking, acting, and violating. This disorder involves a persistent pattern of distorted ways of thinking;

\subsection{Criteria of Antisocial Personality Disorder}

Based on Frederick (2006:6) a pervasive pattern of disregard for and violation of the rights of others, it occurs since age of 15 years, as indicated by three (or more) of the following:

1) Failure to conform to social norms with respect to lawful behaviours as indicated by repeatedly performing acts that are grounds for arrest

2) Deceitfulness, as indicated by repeated lying, using of aliases, or conning others for personal profit or pleasure.

3) Impulsivity or failure to plan ahead

4) Irritability and aggressiveness, as indicated by repeated physical fights or assaults

5) Reckless disregard for safety of self or others

6) Consistent irresponsibility, as indicated by repeated failure to sustain consistent work behaviour or honour financial obligations

7) Lack of remorse, as indicated by being different to rationalizing having hurt, mistreated, or stolen from another.

This disorder appears to someone since the age of 15 years; it is characterized by respecting to lawful behaviour, deceitfulness, impulsivity, irritability and aggressiveness, reckless disregard, consistent irresponsibility and lack of remorse.

\section{Causes of Antisocial Personality Disorder}

Personality disorder appears in someone, because there are any causes that make disturbance psychological in human being. Personality is an emotion, behaviour, and thought. Those are combined to be personality as human being. 
Based on Cowen (2012:144) stating that "More recent twin studies have confirmed the heritability of antisocial behaviour in adults, and have shown that genetic factors are more important in adults than in antisocial children or adolescents where the shared environmental factors dominate". It means that genetic factors are more important that cause antisocial personality disorder.

The exact cause of antisocial personality disorder is not known, but:

1) Genes may make the person vulnerable to developing antisocial personality disorder and life situations may trigger its development.

2) Changes in the way brain functions may have resulted during brain development.

The writer assumes that personality is combination of thought, emotions, and behaviour. On the other side, causes of antisocial personality disorder are genes that make vulnerable and life situation. Change in the way brain function and brain development.

1) Genetic factors are suspected to be influenced since incident of antisocial behaviour is higher in people with an antisocial biological parent.

2) Environmental factors are believed to contribute to the development of antisocial personality disorder since a person whole role model had antisocial tendencies is more likely to develop the disorder.

From the theory above it can be assumed that genetic and environmental factors are the causes of antisocial personality disorder, nevertheless it can influence in other people.

From explanation above the author concludes that causes of antisocial personality disorder can be defined into two factors by genetic and environmental causes. On the other side, genes and changes in the way of brain can influence behaviour. Therefore, antisocial personality disorder appears when adolescent.

\section{Methodology}

The writer completes reference data through reading book in library and also browsing in the internet to make sure the original scientific thereof. This research is using qualitative method, through the approach of watching movie intensively and doing analysis which is undertaken step by step to look for method of the research. 
First, the writer watches "We Need to Talk About Kevin" movie repeatedly until understand correctly about the story and do the analysis intensively starting from kind of aspect psychology. The writer finds the problem in main character to be analysed and investigated psychologically from the main character. Second, after watching the movie including the analysis and investigation of all sides of "We Need to Talk About Kevin" the writer looks for reference form several expert as a main priority to be analysed, especially to support the data. Third, the paper arranges the paper based on the data that the writer has been found

In the beginning the writer looks for the movie carefully; focusing on what the characters do. But it is not easy to analyse over all, it needs a focus on the material, data, and kind of aspects. After which continuing to find out the experts about psychology which is appropriate to the topic of the title.

\section{B. FINDING AND DISCUSSION}

In this part the writer explains more specifically the story about "We Need to Talk About Kevin". This is one of the mysteries that appear dangerous, sad, and afraid and worry. Someone who kills his young sister and father, it also makes a threat to the family that is Kevin (played by Ezra Miller). Kevin is one of the people who has antisocial personality disorder in family; he is a first child of two. The disease appears on Kevin since seventeen years old, he is very sensitive, aggressive, irritability, lacks of remorse, and reckless.

His father has killed by Kevin (played by John C. Reilly) and young sister (played by Ashley Gerasimovich). Kevin was born in good condition of the family, but while growing up in seventeen years old his character and behaviour change sensitively. Kevin's mother (played by Tilda Swinton) often look kevin's behaviour and character who has changed psychologically. Basically, his mother knows that he looks as normal human to do activity.

\section{1) Analysis of Personality Disorder}

In this time the main point of discussion is the analysis of personality disorder. Personality disorder are characterized by rigid, inflexible patterns of thinking and behaviour that begin as early as childhood or adolescence and causing continual distress throughout many areas of a person's life. 
The writer tries to analyse, explain, and answer the statement of the problem. Then will put dialogue of the movie. The first, the writer explains criteria of antisocial personality disorder in the character, the second causes of antisocial personality disorder, and the last Kevin's character influence to others.

\section{2) The Criteria of Antisocial Personality Disorder of Kevin in movie}

One of main points to discuss is personality disorder, antisocial personality disorder is also called psychopath. A person with this disorder is usually aggressive, irresponsible, having no regard, deceitful, committing repeated criminal acts, and showing lack of remorse.

Antisocial Personality Disorder (APD) is a pervasive pattern of disregard for and violation of the rights of others, according to Frederick it is indicated by three or more of its seven criteria. The writer analysis that Kevin at least meets four criteria of APD namely deceitfulness, irritability and aggressiveness, reckless disregard for safety of self or others, and lack of remorse.

\section{(1) Deceitfulness}

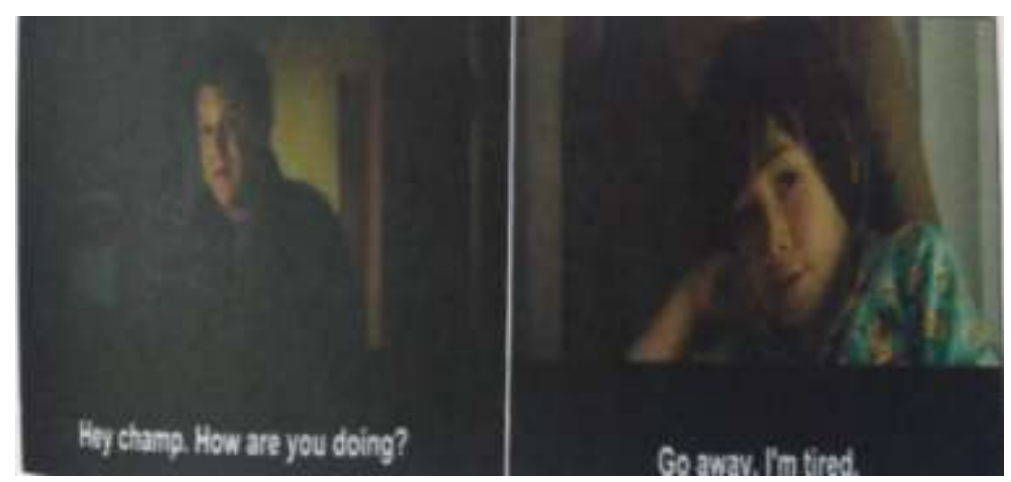

scene 1: Kevin Lies to his father

In the night, in the bedroom (00:56:47-00:57:10)

Father :"Hey champ. How are you doing? Feeling better?"

Kevin :"Go away. I am tired."

Father :"Oh. Okay. Sure thing, buddy. You just get some rest, okay?"

Kevin : "Don't stop reading, mom.” 
The dialogue above means, his father just to make sure Kevin's condition good or bad and look at to Kevin who wants to go to sleep with mom sweetly. Kevin's mom tries to read short a fairy tale, especially to make Kevin go to sleep. It is corresponding to Frederick that deceitfulness is one of criteria of antisocial personality disorder.

The writer concludes that Kevin has lied to his father who says "Go away. I am tired". Which is actually Kevin and mom are reading fairy tale and feeling better, his condition is well and he does want to be disturbed by others.

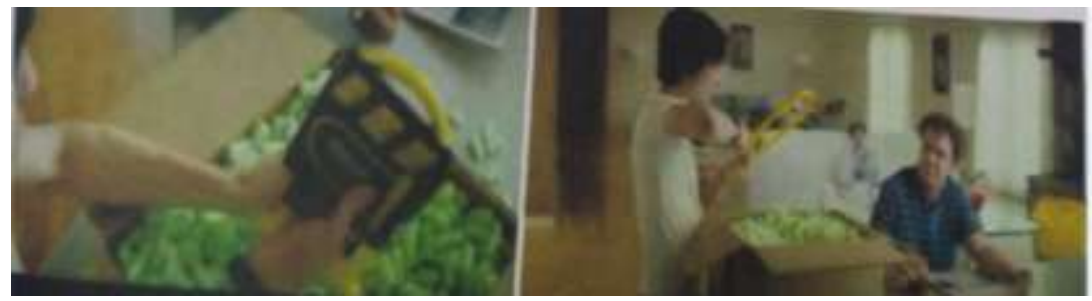

scene 2: Kevin lies about padlock

In the living room

(01:29:37-01:29:50)

Mom

Kevin

them at

Father
: "What are they for? You never ride your bike."

: "I got this for a song the web. I'll make a bundle selling school."

: "Like Donald Trump, huh."

From the dialogue above, mother asked to Kevin "What are they for? You never ride your bike." Kevin got these for a song of the web, especially to make a bundle selling them at school. Mom confused while Kevin buy padlock while Kevin never ride the bike. This dialogues is as an indication that Kevin commits repeated lying, it is corresponding to Frederick that deceitfulness is one of the criteria of antisocial personality disorder.

The writer concludes that actually Kevin buying a padlock is not for a bike, but he is planning to kill several friends trough shooting the arrow in the playground and the padlock is used to lock the whole door. Kevin buys it through online media and his mother never knows about padlock that Kevin buys. It looks 
impossible to his mother, he tries to lie while explaining about thing in the living room.

(2) Irritability and aggressiveness

Irritability and aggressiveness are the indication of antisocial personality disorder by committing repeated physically fights or assaults.

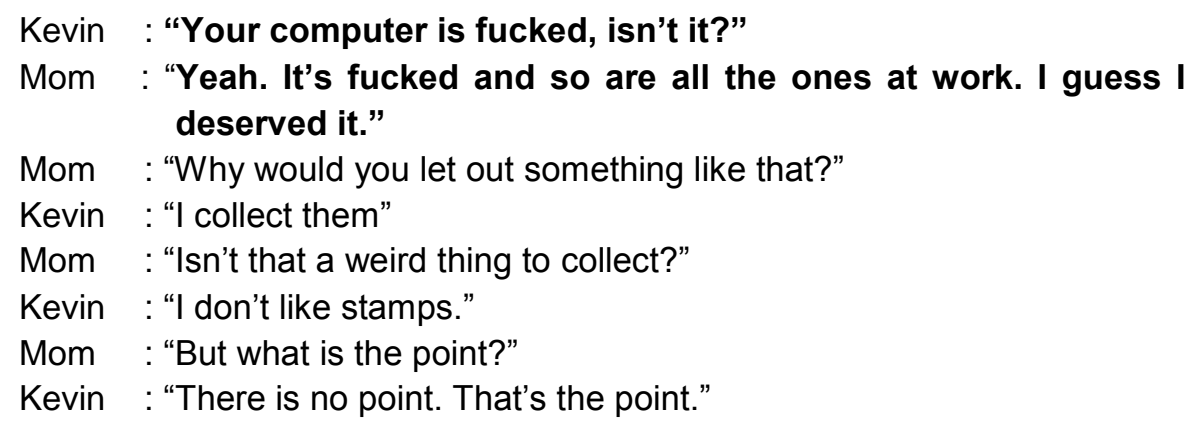

The dialogue above tells that mom's computer damaged system and as Kevin to help repaired it. But, Kevin answer doesn't like about the point which mom says. It seems that Kevin is a sensitive person who does not like something make him disturbed. According to Frederick that irritability and aggressiveness are one of the criteria of antisocial personality disorder. The writer concludes that Kevin is very sensitive and aggressive person, he feels comfort while doing something alone.

\section{(3) Reckless disregard for safety of self or others}

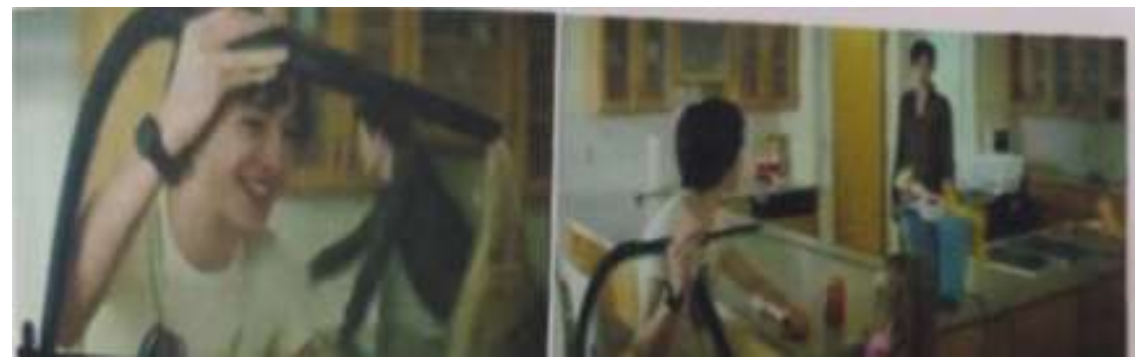

Scene 3: Kevin plays the vacuum In the kitchen (01:03:30-01:04:17)

Celia : "Kevin, you're my friend! You're my friend." 
Kevin : "Beat it, Celia. Get me a soda. No, not that one, you retard. Get me a root beer. Thanks, Celia. I was thirsty."

Kevin : "Hey, you wanna know a secret? Come closer."

Kevin : "Do you know who else thirsty? You don't? It's the vacuum monster."

Mom : "Cut it out!"

In this scene, Celia tries to play with Kevin about Christmas. But, Kevin asks Celia to take out a root beer in the refrigerator. "Get me a root beer. Thanks, Celia. I was thirsty". Then tells Celia who else is thirsty, suddenly Kevin take out vacuum and play Celia's hair. She is shocked and afraid his hair was broken by the vacuum. Celia screams to call mom in order to stop his act. This dialogue is indicated by reckless disregard for safety of self or others according to Frederick.

The writers concludes based on dialogue and behaviour above that Kevin does not care about safety of other especially for Celia, it was a dangerous moment if Celia's hair was broken by vacuum and make her shocked.

\section{3) Kevin's character influence to others characters}

In this scene how Kevin's character influence to others characters through his behaviour when talks to parents.

Father : "Kev, mom had something that she wanted to tell you."

Mother : "I wanted to thank you for calling the ambulance. I was Concerned that you might be feeling responsible."

Kevin : "Why is that?"

Mother : "Because you was supposed to be looking after her."

Father : "We just don't want you to blame yourself."

Kevin : "No. I don't....I mean I...I never said I did."

Mother : "She is gonna need a glass eye, Kevin."

Father : :So, we would appreciate you looking after her and any name-calling."

Kevin : "You don't really remember being a kid much do you, dad? Celia is just gonna have to suck it up

mother : "I though you didn't like those."

Kevin : "Well, they are a...Now what do you call it...an acquired taste." 
The dialogue above tells that mother would like to appreciate to Kevin who has helped Celia with call the ambulance while accident at house. On the other side, Kevin eats fruit in front of mother. But, his behaviour while eat fruit was no respect and make mother to go away from Kevin.

The writer concludes that actually his parents would like to appreciate to Kevin, but his behaviour make mother feel uncomfortable and decide to go away from Kevin. it was so influence psychological of parents, they have to be more patient to communicate with Kevin.

From all dialogues and pictures above, the writer concludes that criteria of antisocial personality disorder of Kevin are deceitfulness, irritability and aggressiveness, reckless disregard for safety of self or others, and lack of remorse. In the problem, people with antisocial personality disorder can do anything what they want, they can also threaten, hurt, and kill. No all people with antisocial personality disorder are criminal and no all criminal is antisocial personality disorder. Kevin killed friends in the auditorium, and father with Celia is the back of yard. Because he was reputed as a freak man and can hurt all the people. Kevin has planned assassination for two weeks ago with buy padlock and executed through the arrow. Therefore, Kevin evident fault by ministry of justice and be a prisoner after kill all the people.

\section{CONCLUSION}

The writers conclude that Kevin has lied to his father who says "Go away. I am tired". Which is actually Kevin and mom are reading fairy tale and feeling better, his condition is well and he wants not to be disturbed by the others. In addition, from the statement that actually Kevin buys a padlock is not for a bike, but planning to kill several friends through shooting the arrow in the playground and the padlock is used to lock the whole door. Kevin buys it through online media and his mother never knows about padlock that Kevin buys. It looks impossible for his mother, he tries to lie while explaining about thing in the living room.

Furthermore, based on the dialogue and behaviour that Kevin does not care about the safety of others especially for Celia, it was a dangerous moment if Celia's 
hair was broken by vacuum and make her shocked. In relation to which, his parents would like to appreciate Kevin, but his behaviour make mother feel uncomfortable and decide to go away from Kevin. It was so influential parents; they have to be more patient to communicate with Kevin.

Finally, the criteria of antisocial personality disorders of Kevin are deceitfulness, irritability, aggressiveness, reckless disregard for safety of self or others, and lack of remorse. In respect of which, people with antisocial personality disorder can do anything what they want, they can also threaten, hurt, and kill. No all people with antisocial personality disorder are criminal and no all criminal is antisocial personality disorder. Kevin killed his friends in the auditorium, and father with Celia is in the back of yard. Because he was reputed as a freak man and can hurt all the people. Kevin has planned assassination for two weeks ago with buy padlock and executed through the arrow. Therefore, Kevin is found guilty and fault by ministry of justice and become a prisoner after killing the people as mentioned hereinabove.

\section{BIBLIOGRAPHY}

Abbot, Porter H.2008. The Cambridge introduction to Narrative Second

Edition. New York: Cambridge University Press.

Artof Man Liness. 2013. What is character. Retrieved from:

http://www.artofmanliness.com/2013/06/25/what-is-character-its-3-true-

qualities-and-how-to-develop-it/ (17 My 2016).

Barsam, Richard and Dave Monahan. 2010. An Introduction to Film Third Edition. London: W.W. Norton \& Company.

Bohner. Charles and Lyman Grant. 2006. Short Fiction: Classic and Contemporary Sixth Edition. United States America: Pearson Prentice Hall.

Cowen, Philip, et al.2012. Shorter Oxford Textbook of Psychiatry Sixth Edition. United Kingdom: Oxford University Press.

Dobbert, Duane L. 2010. Understanding Personality Disorders. United Kingdom: Rowman \& Littlefield Publisher, Inc. 
Elsaesser, Thomas and Warren Buckland. 2002. Studying Contemporary American Film: A Guide To Movie Analysis. United States of America: Oxford University Press Inc.

Feldman, Robert S. 2011. Understanding Psychology Tenth Edition. New York: McGraw-Hill Companies, inc.

Lucke, Margaret. 1998. Schaum's Quick Guide to Writing Great Short Stories. New York: McGraw-Hill Companies, inc.

Mayo Clinic Staff. 2002. Antisocial Personality Disorder. Retrieved from: http://www.mayoclinic.org/disease-conditions/antisocial-personalitydisorder/symptoms-causes/dxc-20198978 (27 May 2016).

Millon, Theodore, et al. 2004. Personality Disorder in Modern Life Second Edition. Canada: John Wiley \& Sons, Inc.

Paul, Emmelkamp. 2007. Personality Disorders. New York: Psychology Press Psychcentral. 2012. Antisocial Personality Disorder Symptoms. Retrieved from: http://psychcentral.com/disorders/antisocial-personality-disordersymtoms/ (26 May 2016)

Psychology today. 2010. Antisocial Personality Disorder Condition. Retrieved from: https://www.psychologytoday.com /conditions/antisocialpersonality-disorder (27 May 2016).

Rotgers, Frederick and Michael Maniacci. 2006. Antisocial personality Disorder: A Practitioner's Guide to Comparative Treatments. New York: Springer Publishing Company.

Weiner B, Irving and George Stricker. 2003. Handbook of Psychology, Clinical Psychology. Canada: John Wiley \& Sons, Inc.

Wood, C Jeffey. 2010. The Cognitive Behavioural Therapy Workbook for Personality Disorder: A Step-By-Step Program. Canada: New Harbinger Publications, Inc. 